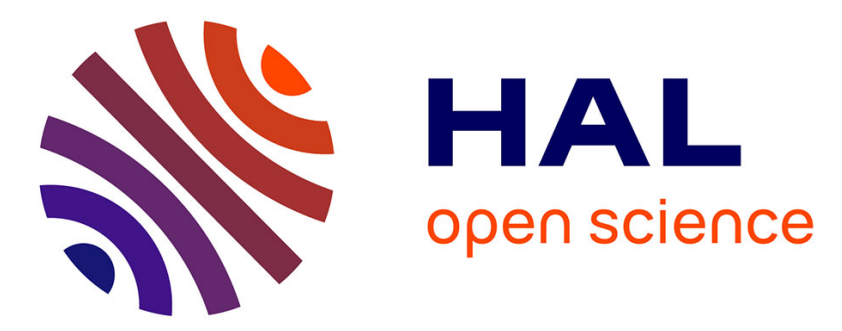

\title{
Integrity control for high temperature structural applications
}

\author{
W. Becker, W. Kerfin, A. Pradier, U. Trabandt, W. Vogel
}

\section{To cite this version:}

W. Becker, W. Kerfin, A. Pradier, U. Trabandt, W. Vogel. Integrity control for high temperature structural applications. Journal de Physique IV Proceedings, 1993, 03 (C7), pp.C7-1911-C7-1916. 10.1051/jp4:19937305 . jpa-00251949

\section{HAL Id: jpa-00251949 https://hal.science/jpa-00251949}

Submitted on 1 Jan 1993

HAL is a multi-disciplinary open access archive for the deposit and dissemination of scientific research documents, whether they are published or not. The documents may come from teaching and research institutions in France or abroad, or from public or private research centers.
L'archive ouverte pluridisciplinaire HAL, est destinée au dépôt et à la diffusion de documents scientifiques de niveau recherche, publiés ou non, émanant des établissements d'enseignement et de recherche français ou étrangers, des laboratoires publics ou privés. 


\title{
Integrity control for high temperature structural applications
}

\author{
W. BECKER, W. KERFIN* ${ }^{*}$ A. PRADIER ${ }^{* *}$, U. TRABANDT and W.D. VOGEL \\ Dornier $\mathrm{GmbH}$ \\ ${ }^{*}$ Dornier Luftfahrt $\mathrm{GmbH}$ \\ ${ }^{* *}$ ESA/ESTEC
}

\begin{abstract}
High temperature composite materials in combination with advanced design and manufacturing concepts are becoming more and more important for space transportation systems like hypersonic flight and reusable reentry vehicles.

In order to meet the challenging demands for thermostructural applications Carbon/Carbon and Ceramic Matrix Composites are the most promising materials with respect to weight, stiffness, strength and heat resistance.

An ESA supported study has been undertaken to define an Integrity Control Methodology for thermostructural elements made from these high temperature composite materials.
\end{abstract}

\section{INTRODUCTION}

Innovative design approaches for space transportation in Europe are the challenging requirements of hpyersonic flight and reusable reentry vehicles. While operating in different speed and temperature regimes, both applications pose related problems with regard to airframe components, tank structures, and propulsion systems.

The design objective is, in all instances, the production of highly efficient and safe structures which exploit the full potential of high temperature composite materials in combination with advanced design and manufacturing concepts. Thermostructural applications of reinforced carbon-carbon and ceramic matrix composites have emerged in the aerospace industry to meet these modern demands. Operation at high temperatures means that these materials systems may undergo microstructural changes, as well as experience mechanical and/or thermal loading damage and environmental surface attack.

The definition of an Integrity Control Methodology and its implications for design, analysis and testing of thermostructural elements made from C/C and CMCs is therefore of paramount importance.

Under consideration of global deviations and local imperfections inherently existing in $\mathrm{C} / \mathrm{C}$ and CMCs and under recognition of the specific failure mechanisms of high temperature composites, a study has been initiated to address the relevant issues associated with Integrity Control for high temperature structural applications. This paper will give a description of the Integrity Control Approach, criteria for the material and structural design and some preliminary results obtained from investigations of non-destructive inspection methods. 


\section{Integrity Control Approach}

Integrity control for high temperature composites is intended to happen in different ways and at different stages. A respective integrity control approach is summarized by the flow-chart of Fig. 1.

Integrity control begins with the actual material design, that means e.g. the choice of fiber and matrix and the characterizing micromechanical parameters. From this, the composite material properties result, including the specific damage and fracture behaviour. In this connection a profound micro-macromechanical analysis allows the development of ceramic matrix composites with optimized mechanical properties.

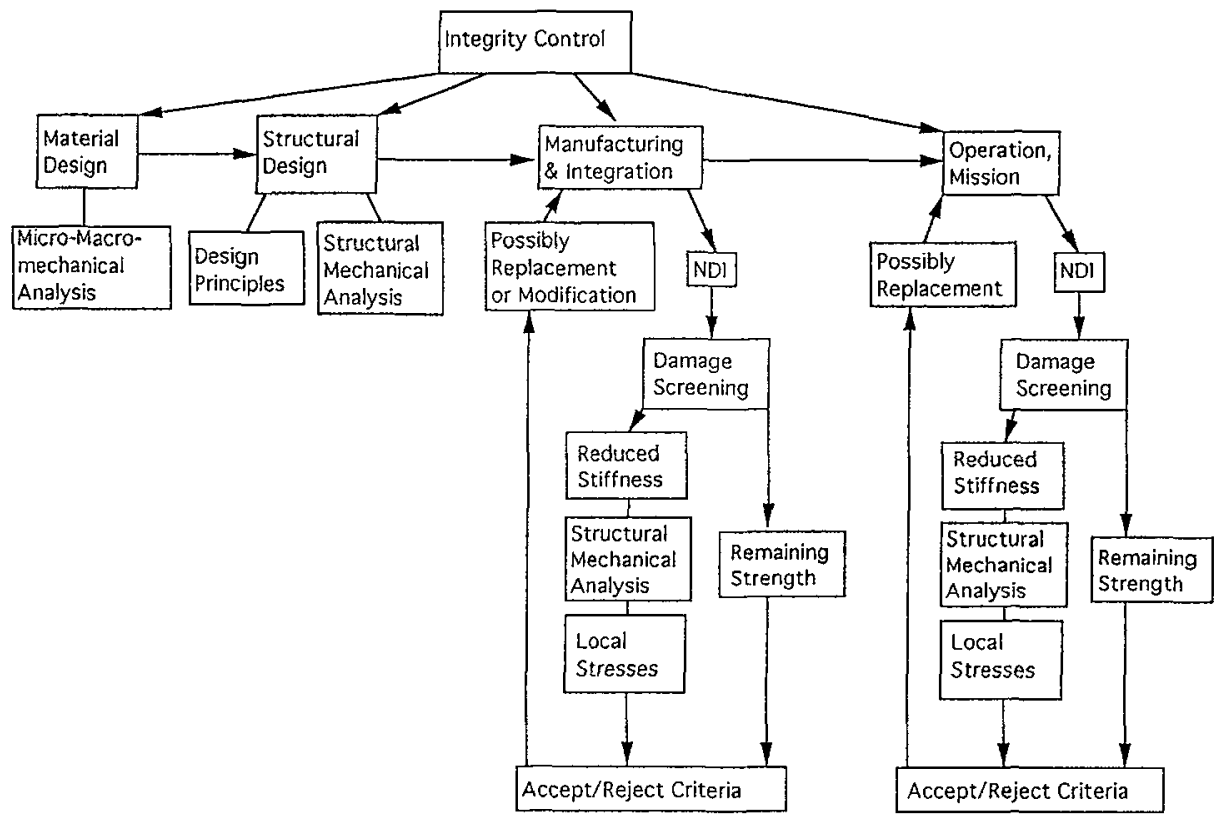

Figure 1: Integrity Control Approach

Following this, the actual structural design has to take into account the specific characteristics of high temperature composites. To this end, certain design principles have to be obeyed. Eventually, the resultant design behaviour is to be investigated in detail by respective structural mechanical analyses.

Then, integrity control has to take place after both manufacturing and a performed operation of a high temperature structure. For that purpose, in both cases non-destructive inspection (NDI) has to be applied. The monitored damage affects both the resultant local stresses and the residual material strength. The assessment of the actually occurring stresses in comparison with the remaining strength is the basis for accept/reject criteria, which for their part possibly lead to the replacement of structural components.

\section{Material Design}

In order to understand, predict and optimize the damage and fracture behaviour of ceramic matrix composites available, micromechanical models have been reviewed in detail [1] - [5]. Thereby, among others, the following micromechanical parameters play an important role: the fiber radius $r$, the fiber and matrix volume fractions $v_{f}$ and $V_{m}$, the fiber and matrix elastic moduli $E_{f}$ and $E_{m}$, the fiber-matrix shear resistance $\tau$, the critical stress intensity factor of the matrix $k_{0}$, the fiber strength $S$ in the 
case where the latter is unique and the statistical quantities $\sigma_{0}, L_{0}$ and $m$ in the case where the fiber strength is given by a Weibull distribution ( $m$ = Weibull exponential parameter). From these micromechanical parameters in the end the macromechanical material characterizing quantities result, including, among others: the matrix microcracking strain and stress $\epsilon_{m c}$ and $\sigma_{m c}$, the ultimate composite strength $\sigma_{u}$, the effective composite fracture toughness $K_{I c}$, and the mean fiber pullout length $\langle L\rangle$.

According to Marshall and $\operatorname{Cox}[5]$ e.g. the fracture toughness for an instably extending penny-shaped crack is given by

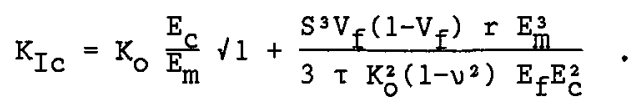

For the theoretical tensile strength $\sigma_{u}^{\text {theor. }}$ of an unidirectional ceramic matrix ply with multiple matrix microcracking Curtin [3] e.g. has derived the following relationship:

$$
\sigma_{\mathrm{u}}^{\text {theor }}=\mathrm{v}_{\mathrm{f}}\left[\frac{\sigma_{\mathrm{o}}^{\mathrm{m}} \mathrm{L}_{\mathrm{o}}{ }^{2}}{\mathrm{r}(\mathrm{m}+2)}\right]^{1 / \mathrm{m}+1} \frac{\mathrm{m}+1}{\mathrm{~m}+2} \text {. }
$$

For other macroscopic material characterizing quantities, respective micro-macromechanical results are available too [1] - [6].

The benefit of all these relations is that they allow us to study easily the effect of varying micromechanical parameters on the resultant macromechanical properties. In the end this enables the well-aimed optimization of macromechanical material performance.

As an actual example, a C/SiC composite with the following micromechanical characteristics be given:

$$
\begin{array}{lll}
\mathrm{r}=5 \mu \mathrm{m}, & \mathrm{V}_{\mathrm{f}}=0.5, & \mathrm{~V}_{\mathrm{m}}=0.5, \\
\mathrm{E}_{\mathrm{f}}=300000 \mathrm{MPa}, & \mathrm{E}_{\mathrm{m}}=40000 \mathrm{MPa}, & v=0.3, \\
\tau=4 \mathrm{MPa}, & \mathrm{K}_{\mathrm{o}}=2 \mathrm{MPa} \sqrt{\mathrm{m},} & \mathrm{S}=5000 \mathrm{MPa}, \\
\mathrm{L}_{\mathrm{o}}=20 \mathrm{~mm}, & \sigma_{\mathrm{o}}=5000 \mathrm{MPa}, & \mathrm{m}=7 .
\end{array}
$$

The relations (1) and (2) give the following predictions for the fracture toughness $\mathrm{K}_{\mathrm{Ic}}$ and the theoretical ultimate strength $\sigma_{\mathrm{u}}^{\text {theor }}$

$$
\mathrm{K}_{\mathrm{Ic}}=44.5 \mathrm{MPa} \sqrt{\mathrm{m}}, \sigma_{\mathrm{u}}^{\text {theor. }}=2130 \mathrm{MPa} \text {. }
$$

With a slightly increased fiber strength of $6000 \mathrm{MPa}$ and a reduced shear resistance of $2 \mathrm{MPa}$ the fracture toughness can be improved to $\mathrm{K}_{\mathrm{Ic}}=81.6 \mathrm{MPa} \sqrt{\mathrm{m}}$ and the ultimate strength becomes $2290 \mathrm{MPa}$.

In general, the involved micromechanical parameters of course cannot be varied arbitrarily, but, due to availability and processing feasibility, their range is often rather limited. Nevertheless, as far as parameter variation is possible, in many cases a considerable additional material potential can be exploited.

\section{Structural Design}

Due to the specific behaviour of ceramic matrix composites in the design of actual structural components, a number of particular design criteria have to be taken into account.

First, the temperature stability of the material and the applied oxidation protection should be confirmed to be really sufficient for the intended application. Next, the maximal occurring stresses $\sigma_{\max }$ in the structure have to keep below the actual ultimate strength $\sigma_{\mathrm{u}}$ :

$$
\sigma_{\max }<\sigma_{\mathrm{u}}
$$


If possible, the applied stresses should also be below the critical stress value $\sigma_{\mathrm{mc}}$ where multiple matrix-microcracking occurs:

$$
\sigma_{\max }<\sigma_{\mathrm{mc}} \cdot
$$

If $\sigma_{m c}$ is too small for an upper stress limit then multiple matrix-microcracking has to be tolerated and the accompanying stiffness loss has to be taken into account in structural analyses.

Compared to fiber reinforced polymers, the performance of unidirectional ceramic matrix composites is relatively poor for inplane shear and for transversal tensile loading. Therefore, in the case of multiaxial stress states, the use of various different fiber orientations is advisable, as e.g. the use of a quasi-isotropic $\left[0^{\circ} / \pm 45^{\circ} / 90^{\circ}\right] s^{-l a y-u p .}$

A very critical aspect for the application of ceramic matrix composites is their low interlaminar shear strength. Therefore, in an actual structural CMC design the occurring interlaminar shear stresses have to be analysed carefully. For this purpose e.g. the finite element code ABAQUS has been found appropriate. In order to keep the interlaminar shear stresses low, the structural design should try to transfer external forces and reaction forces as directly as possible to laminate inplane forces.

Eventually, in connection with the low interlaminar shear strength, a relatively high tendency to free edge delamination ("free edge effect") can be the consequence and has to be taken into account. For this purpose the use of lay-ups is advisable where the lay-up angles of adjacent layers do not differ too much. In this sense a $\left[0^{\circ} / 45^{\circ} /\right.$ $\left.90^{\circ} /-45^{\circ}\right]_{\mathrm{s}}$-laminate should be preferred to a $\left[0 \% / 90^{\circ} / 45^{\circ} /-45^{\circ}\right]$ s-laminate.

\section{Manufacture of CMC Materials}

In the Integrity Control study, three different types of CMC materials are used:

- Carbon fibre reinforced carbon (C/C)

- Carbon fibre reinforced siliconcarbide (C/SiC)

- Siliconcarbide fibre reinforced siliconcarbide ( $\mathrm{SiC} / \mathrm{SiC}$ )

The C/C material is a commercially available product (CF 222) from Schunk company, Germany. C/SiC and SiC/SiC materials are produced by Dornier and represent the materials standard of the first quarter in 1992.

\section{C/C Material}

Generally, C/C is manufactured according to the following route: First, woven fabrics are impregnated by a suitable matrix precursor. The next step is a pressing and/or a curing cycle, followed by carbonization between 800 to $1200^{\circ} \mathrm{C}$ in inert atmosphere. After the carbonization treatment further heat treatment to graphitization temperatures of $1900-2500^{\circ} \mathrm{C}$ can be performed. The result is a porous carbon/carbon composite with approximately $30-35 \%$ open porosity, which can be decreased to less than $5 \%$ by densification cycles. These cycles may consist of the steps impregnation/ recarbonization or impregnation/recarbonization/regraphitization. Instead of the densification via liquid precursors, chemical vapor impregnations (CVI) of pyrolithic carbon into the porous skeleton can also be performed to fill the interior pore spaces.

\section{$\mathrm{C} / \mathrm{SiC}$ and $\mathrm{SiC} / \mathrm{SiC}$ Materials}

The manufacture of both $\mathrm{C} / \mathrm{SiC}$ and $\mathrm{SiC} / \mathrm{SiC}$ materials, developed by Dornier, follows the same procedure. The principle is to impregnate continuous fibres (C or SiC) with a slurry consisting of a Si-organic polymer, a solvent and a ceramic powder (typically $\mathrm{SiC}$ ), to form prepregs by winding them on a big mandrel, to laminate the prepregs to the desired shape and to convert the polymer into the ceramic material by curing under autoclave conditions and pyrolysis in a pressureless way without forming tools. This process results in a material with about $30 \%$ porosity due to shrinkage of the Siprecursor. Reinfiltration steps (followed by curing and pyrolysis) lead to a marked improvement of mechanical performance. The interlaminar shear strength especially is increased by more than a factor of 3 for three infiltration cycles. 
The advantages of this fabrication route are: short time manufacturing route compared to the CVI route, flexibility in shape and design, realisation of large structures, manufacture even of integrated structures.

\section{Defect Assessment and Non-Destructive Inspection}

No material is free from flaws. Likewise, all structures contain defects and may experience damage growth during operational use, either by the propagation of existing defects or by accident. Depending on the type of material and the processing or manufacturing route used, very different defects may occur.

Typical non-homogeneities and defects related to thermostructural elements made from Carbon/Carbon and Ceramic Matrix Composites have been established and characterized. For the detection of non-homogeneities and defects, Non-Destructive Inspection methods have been assessed in detail. The application of common NDI-methods to CMC materials is a field of new experience, in particular in connection with the specific microstructure of CMC materials (as e.g. the high degree of porosity).

Among a number of preselected NDI-methods, essentially two have been found to be well applicable to CMC materials, namely

- radiography methods and

- ultrasonic inspection methods.

Among the radiography methods, both normal radiography and microfocus radiography have been applied to CMC materials. In doing so, the radiography inspection turned out to be best suitable to monitor density changes and thus varying porosity or distinct flaws. It is less suitable to detect pure inplane cracks or delaminations. Any delamination induced by impacts can be very well detected by the accompanying matrix cracks.

As normal radiography is rather cheap and easy to apply it is recommended to apply it for CMC structural parts already in the green state (as a step of quality assurance). This allows us to renounce on the pyrolysis of parts that already have significant defects.

The application of ultrasonic inspection, on the other hand, is less suitable to monitor density variations but it allows us to detect delaminations and to localize their depth with respect to the thickness direction. Ultrasonic testing can be applied in different modes, namely as through transmission mode and as pulse echo mode.

Thereby, the detection of delamination zones has only been made possible in through transmission (low frequency transducer e.g. $0.3 \mathrm{MHz}$, dry coupling). Due to the porosity content of the material, the ultrasonic technique in pulse echo mode is not as easy to apply. Thus the advantage of this method, to be applicable for integrated structural parts that are accessible only from one side could not be exploited. Ultrasonic inspection in pulse echo mode should be used for green parts to prove the laminate quality. In this state of manufacture, the application of USPE is possible with very good resolution and sensitivity.

A test programme has been set up to determine the mechanical properties under static/ cyclic loads and different temperature conditions up to $1600^{\circ} \mathrm{C}$ of test samples containing hole type defects. Damage monitoring will be made possible by the application of the selected NDI techniques prior to and after testing (thermal cycles see Fig. 2).

\section{Validation on Structural Component}

In the development process of an actual design, structural mechanical analyses play an important role. To this purpose the finite element code ABAQUS has been chosen and tested. This code is capable of determining and monitoring the resultant interlaminar shear stresses at arbitrary integration points through the cross section of a laminate element. For the calculation of interlaminar shear stresses a C/SiC manufactured heat shingle has been taken as an example, the respective finite element mesh is shown in Fig. 3 . 

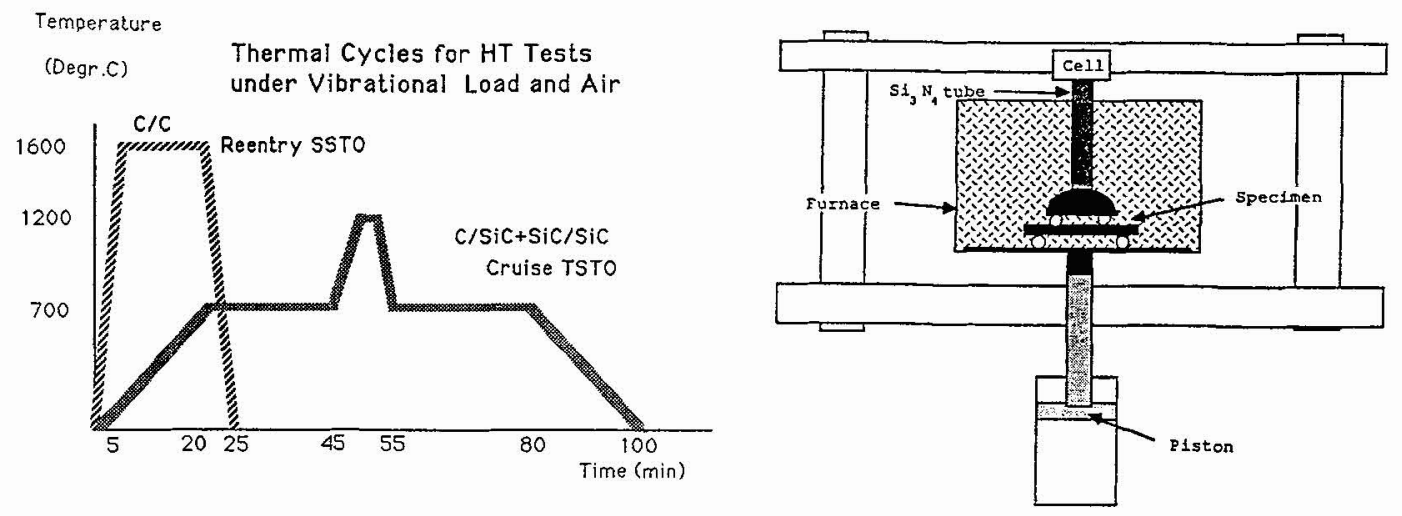

Figure 2: Thermal Cycle and Test Set-up

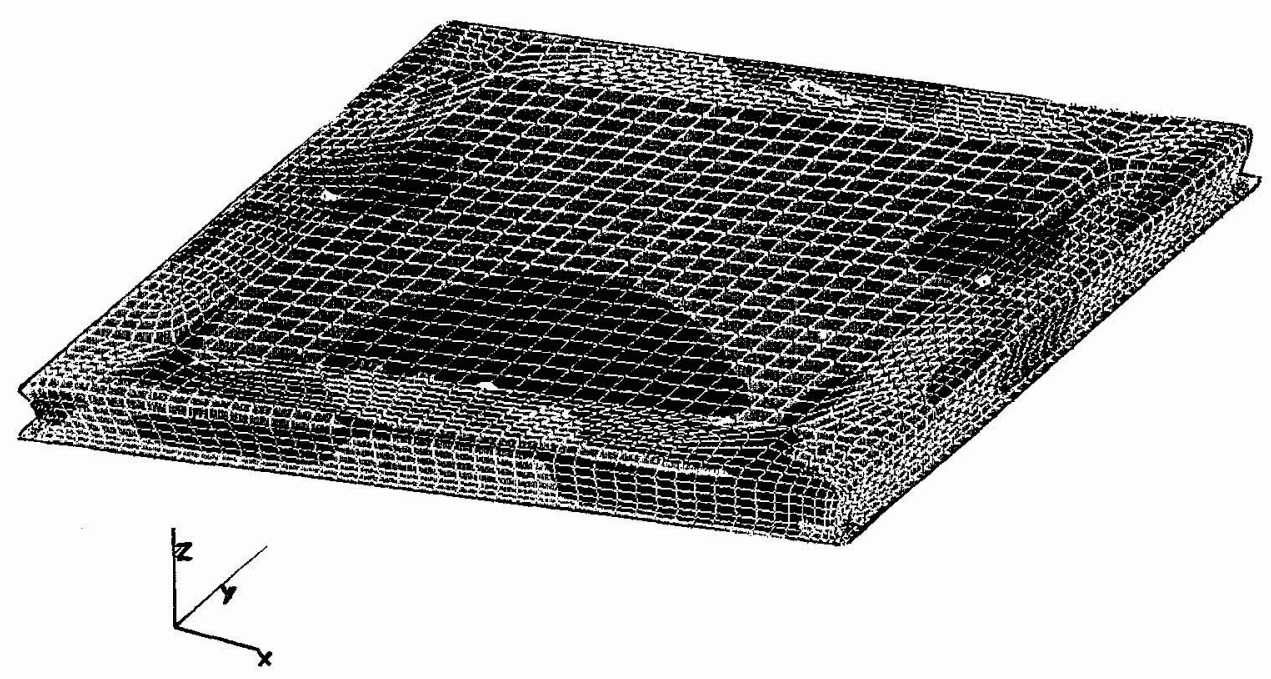

Figure 3: Finite Element Mesh and Resultant Transversal Force $\mathrm{O}_{\mathrm{y}}$

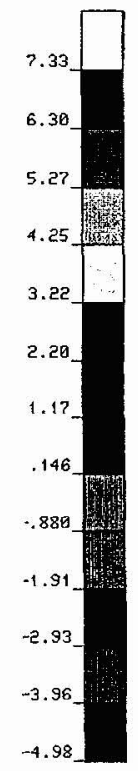

\section{REFERENCES}

[1] Aveston, J., Cooper, G.A., Kelly, A.: Single and Multiple Fracture. In: "The Properties of Fiber Composites", Conference Proceedings of the National Physical Laboratory, IPC, 1971, pp. 15-26.

[2] Budiansky, B., Hutchinson, J.W., Evans, A.G.: Matrix Fracture in Fiber-Reinforced Ceramics. J. Mech. Phys. Solids Vol. 34 (1986) No. 2, pp. 167-189.

[3] Curtin, W.A.: Theory of Mechanical Properties of Ceramic-Matrix Composites. Journal of the American Ceramic Society Vol. 74 (1991) No. 11, pp. 2837-2845.

[4] Evans, A.G. and Marshall, D.B.: Overview No. 85 - The Mechanical Behaviour of Ceramic Matrix Composites. Acta metall. Vol. 37 (1989) No. 10, pp. 2567-2583.

[5] Marshall, D.B. and Cox. B.N.: Tensile Fracture of Brittle Matrix Composites: Influence of Fiber Strength. Acta metall. Vol. 35 (1987) No. 11, pp. 2607-2619.

[6] Haug, T., Ostertag, R., Schäfer, W.: Fiber Reinforced Ceramics for Aerospace Applications. In "Advanced Materials and Structures from Research to Application", SAMPE European 1992, edited by J. Brandtz et al, Switzerland. 